\title{
ASSOCIATION BETWEEN PRURITUS WITH SERUM CALCIUM, PHOSPHATE LEVELS AND CA-PO4 PRODUCT IN CHRONIC KIDNEY DISEASE (STAGE- 5) PATIENTS ON MAINTENANCE HEMODIALYSIS
}

\author{
HASAN R ${ }^{1}$, CHOWDHURY MN ${ }^{2}$, RAHMAN MM ${ }^{3}$, ISLAM MN ${ }^{4}$, ANWAR ASMT ${ }^{4}$, WAZIB A ${ }^{5}$,
} SHAMS $\mathrm{T}^{6}$, RAHMAN MS ${ }^{7}$, ANOWAR $\mathrm{SMI}^{8}$, MAJUMDER AR ${ }^{9}$

\begin{abstract}
Background: Hemodialysis is one of the treatment of end stage renal disease. Disturbance in calcium and phosphate metabolism are observed in these patients. One of the most common cutaneous manifestations in patients on hemodialysis is pruritus. The aim of this study is to evaluate the association between pruritus with serum calcium and phosphate levels in these patients.

Methods: This analytic, descriptive, cross-sectional study was performed in 2014 over 191 patients of maintenance haemodialysis. Information related to the patients age, gender, residence, pruritus, duration and frequency of dialysis, was extracted from questionnaires. Serum levels of calcium, phosphate and albumin were measured \& data were analyzed.

Results: $68 \%$ of the patients had pruritus, of whom $48.2 \%$ had serum calcium levels below the normal range. The Mean \pm SD of serum calcium, phosphate, Ca-PO4 product, and duration of dialysis were $8.77 \pm 1.22 \mathrm{mg} / \mathrm{dl}, 3.82 \pm 1.18 \mathrm{mg} / \mathrm{dl}, 34.17 \pm 12.69$, and $18.01 \pm 11.94 \mathrm{months}$ respectively in patients with pruritus and $9.24 \pm 1.15 \mathrm{mg} / \mathrm{dl}, 3.40 \pm 1.36 \mathrm{mg} / \mathrm{dl}, 35.75 \pm 13.02$, and 17.84 \pm 16.01 months respectively in patients without pruritus. Our study showed that most patients with pruritus had serum calcium levels in the below normal range.
\end{abstract}

Conclusion: Good control of serum calcium levels may have a role in reducing uraemic pruritus.

Keywords: ESRD, Calcium, phosphate, Ca-PO4 product, hemodialysis, pruritus.

\section{Introduction}

End Stage Renal Disease (ESRD) is one of the main health problems of the communities worldwide. Chronic kidney disease (CKD) has a progressive course in most cases, and final results may be End Stage Renal Disease. Various treatments have been considered for these patients, and one of the main options is hemodialysis (HD). ${ }^{1}$ The incidence of CKD is increasing rapidly. According to the data of Bangladesh Renal Registry report almost twenty millions of Bangladeshi adults are suffering from various stages of CKD. In Bangladesh approximately $100-120$ patients per million populations (PMP) reach End Stage Renal Disease (ESRD) every year. ${ }^{2}$ Rennke HG et al. (2010), showed that over 500000 patients live with ESRD in the United State, of whom $72 \%$ have undergone long-term dialysis and 28\% have received kidney transplantation. ${ }^{3}$ Patients with CKD who are on treatment with HD suffer from various cutaneous lesions, which often

1. Dr. Rafiqul Hasan, Assistant Professor, Cox'sbazar Medical College.

2. Dr. Md Nizamuddin Chowdhury, Professor and Head, department of Nephrology, DMC.

3. Dr. M Muhibur Rahman, Professor and Head, department of Nephrology, SSMC.

4. Dr. ASM Tanim Anwar, Registrar, department of Nephrology, DMC.

5. Dr. Amit Wazib, Junior consultant, department of Neurology, DMC.

6. Dr. Tarek Shams, Medical officer, CMC.

7. Dr. Md. Saidur Rahman, Student (MD Thesis part), Department of Nephrology, Dhaka Medical College Hospital, Dhaka

8. Dr. SM Imrul Anowar, Assistant Registrar, National Institute of Kidney Diseases and Urology (NIKDU)

9. Dr. Arifur Rahman Majumder, Assistant Registrar, National Institute of Kidney Diseases and Urology (NIKDU)

Correspondence: Dr. Rafiqul Hasan, Assistant Professor, Cox'sbazar Medical College

Received: 12 May 2018

Revision: 26 August 2018

Accepted: 08 September 2018

https://doi.org/ 10.3329/jdmc.v27i2.45824 
annoy them. $88 \%$ of CKD patients had some form of skin disorder; pallor was the most common $(82 \%)$, while xerosis $(61 \%)$, pruritus (53\%), pigmentation (37\%) and bacterial infection (37\%) were other common problems. ${ }^{4}$ These cutaneous manifestations may be related to uremia, previous underlying disease, drugs and/or HD treatment. ${ }^{5}$ One of the most common cutaneous menifestation seen in patients on HD is pruritus, the prevalence of which in patients with CKD is between $37 \%$ to $90 \%$; this rate is about $80 \%$ in patients on HD. ${ }^{6}$ The mechanisms of underlying uraemic pruritus are not exactly known and it appears that multiple combined factors integrate in the pathogenesis of this condition. ${ }^{7}$ It may be associated to renal insufficiency, secondary hyperparathyroidism, xerosis, increased serum levels of magnesium, calcium, phosphate, aluminium, histamine, proliferation of nonspecific enolase-positive sensory nerves in the skin, hypervitaminoses A and iron deficiency anemia. $^{8,9}$ The pathophysiology of uraemic pruritus is complex and many uraemic and nonuraemic factors contribute to its development. Two hypotheses on the underlying pathophysiological mechanisms of uraemic pruritus(UP) have been postulated - the immunohypothesis and the opioid hypothesis and these have been strengthened somewhat by the results of clinical trials. According to the immunohypothesis, uraemic pruritus(UP) may be an inflammatory systemic disease rather than a local skin disorder. ${ }^{10-12}$ The opioid hypothesis proposes that UP is partly a result of changes in the endogenous opioidergic system, with overexpression of opioid $\mu$ receptors in dermal cells and lymphocytes. ${ }^{13}$ Overactivity of the opioid $\mu$-receptor (and concomitant downregulation of opioid êreceptors) might be caused by the increased serum â-endorphin to dynorphin ratio observed in patients with CKD and could explain the development of UP. ${ }^{14}$ Parathormone and ions (e.g. calcium, phosphate and magnesium ions) have also been implicated in the pathogenesis of uraemic pruritus, as itching frequently accompanies severe secondary hyperparathyroidism and an elevated calciumphosphate product. Xerosis (dry skin) can facilitate the development of UP in patients with CKD. Abnormalities in calcium and phosphate metabolism in ESRD has been claimed to provide an explanation for uraemic pruritus. Hyperparathyroidism with secondary hypercalcemia and skin calcification may stimulate mast cell degranulation with consequent release of histamine may play a role in uraemic pruritus. Microprecipitation of calcium, phosphate in the skin might be one of the causative factors in uraemic pruritus. ${ }^{15}$

In normal skin calcium ion concentration increases towards the outer epidermis, forming a calcium gradient within the epidermis. ${ }^{16}$ In CKD patients, the calcium ion concentration in the deeper layer of the epidermis was significantly higher in the pruritus group than in the non-pruritus group. Also in the pruritis group, calcium ions were distributed equally in all layers except for the stratum corneum, which indicated disruption of the calcium gradient. In another study, haemodialysis patients with pruritis had increased calcium ions in the extracellular fluid around the receptors of sensory nerve endings. ${ }^{17}$

Calcium ion concentrations in extracellular fluid have been shown to influence sensory nerve terminals either directly by voltage-sensitive ion channel gates according to the surface potential theory or through indirect mechanisms. ${ }^{18}$ Threshold for sensing pruritus stimuli may be lowered by changes in the impulse activity of unmyelinated $\mathrm{C}$-nerve fibres, which transmit and integrate pruritus, pain and cold sensations. ${ }^{19}$ Therefore, high calcium ions in the extracellular fluid of the inner layer of the epidermis may stimulate excessive production of cytokines that induce the release of pruritogenic substances. ${ }^{20}$

\section{Materials and methods}

This descriptive-analytic, cross-sectional study was conducted on 191 patients who were on HD for more than 3 months at the Department of Nephrology, Dhaka Medical College Hospital $(\mathrm{DMCH})$, National Institute of Kidney Diseases and Urology (NIKDU) and Bangabandhu Sheikh Mujib Medical University (BSMMU), Dhaka, in 2014. Data were collected from questionnaires regarding age, gender, residence and sign 
symptom of CKD such as weakness, pruritus, anaemia, vomiting, hyperpigmentation, hypertension etc. History of taking significant drugs (such as opioids, steroid, anticonvulsants, chloroquine), patients who were previously diagnosed as a case of AIDS, internal malignancy, hypothyroidism, hyperthyroidism, lymphoma, polycythaemia rubra vera, psychiatric illness, skin diseases (such as scabies, psoriasis, eczema, tineasis),patients with clinically detectable jaundice and patients with sign symptom of hypothyroidism or hyperthyroidism (Weight gain or loss, persistent diarrhoea or constipation, heat or cold intolerance, croaky voice) were excluded as a case.Ca was measured by CPC and a spectrophotometer; albumin and $\mathrm{PO}_{4}$ by the ultraviolet technique. Data were analyzed by the chi-square test, Fisher's exact test and Student's unpaired T-test with SPSS16 software. A $P$-value of less than 0.05 were considered as being statistically significant.

\section{Result}

Total 191 patients on HD were studied. Majority of the patients aged between 35 and 55 years, from urban areas, were male, [Table É]. Figure 1 indicates the different etiology of CKD in study population. Pruritus was found in only 129 patients (68 percent) showed in figure 2. No significant association was found between pruritus with different age group or gender. In this study, 60 percent subjects were hypocalcaemic , 33 percent subjects had normal serum calcium 7 percent subjects were hypercalcaemic. Statistically significant association was found between hypocalcaemia and pruritus (Odds ratio 4.22, $\mathrm{p}<0.01$ ). No such association was found between normocalcaemia or hypercalcaemia and pruritus[Table 2]. 45 percent of study subjects had normal serum phosphate, 33 percent were hypophosphataemic and 22 percent were hyperphosphataemic. No significant association was found between serum phosphate level and pruritus[Table 3]. In this study, 91.6 percent subjects had serum calcium phosphate product d" $55 \mathrm{mg}^{2} / \mathrm{dl}^{2}$ and in 8.4 percent it was $>55$ $\mathrm{mg}^{2} / \mathrm{dl}^{2}$. No significant association was found between serum calcium-phosphate product and pruritus [Table 4].
Table-I

Basic demographic variables of the study population.

\begin{tabular}{llcc}
\hline Variable & Data & Frequency & Percentage \\
\hline Age & Below 35 yrs & 41 & 21.5 \\
& 35-55 yrs & 86 & 45.0 \\
\multirow{4}{*}{ Sex } & Above 55 yrs & 64 & 33.5 \\
\multirow{4}{*}{ Residence } & Male & 113 & 59.2 \\
& Female & 78 & 40.8 \\
& Rural & 65 & 34.0 \\
& Urban & 126 & 66.0 \\
\hline
\end{tabular}

Majority of the patients aged between 35 and r. ...... s....................... males.

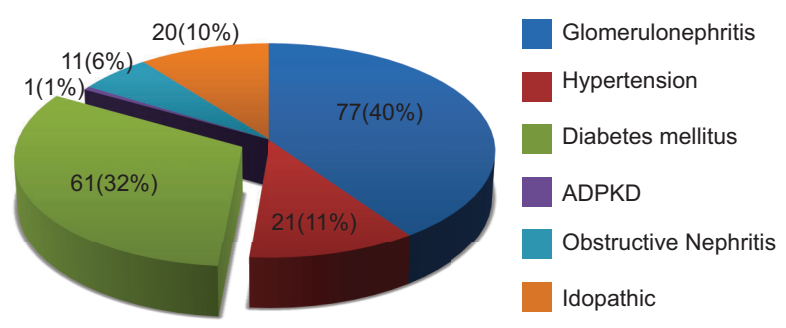

Fig.-1: Etiology of CKD

Figure- 1 shows the etiologyof the CKD in the study subjects. Glomerular disease $(77,40 \%)$ was the most prevalent cause, followed by diabetes mellitus $(61,32 \%)$ and hypertension $(21,11 \%)$.

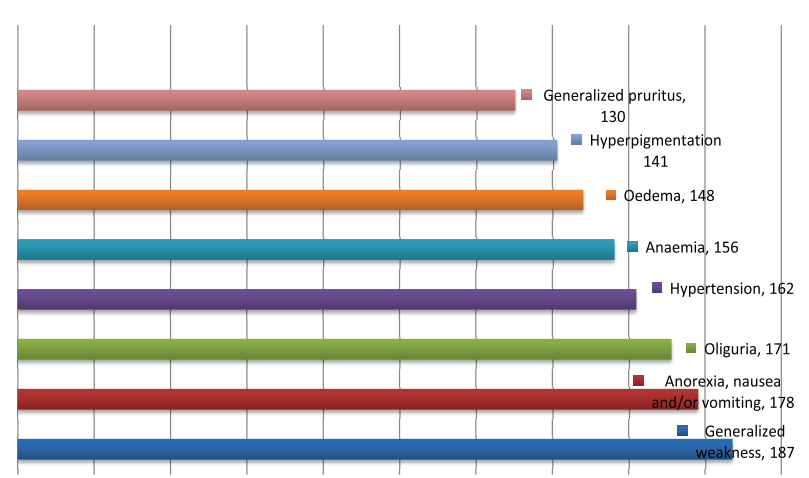

Fig.-2: Clinical features of CKD

Figure-2 shows the clinical features of the patients under study. Generalized weakness was the most common clinical feature found in 187 (98\%) patients. Other common features were gastrointestinal symptoms (anorexia, nausea and vomiting), oliguria, hypertension, anaemia, oedema and hyperpigmentation found in $178(93 \%), 171(90 \%), 162(85 \%), 156(82 \%)$, $148(78 \%)$ and $141(74 \%)$ respectively. Pruritus was found in 129 patients (68\%). 
Table-II

Association of serum calcium level with pruritus.

\begin{tabular}{lcccccc}
\hline Serum calcium & Total & $\begin{array}{c}\text { Pruritus } \\
\text { Present } \\
\left(\mathrm{n}_{1}=129\right)\end{array}$ & $\begin{array}{c}\text { odds ratio } \\
\text { Absent } \\
\left(\mathrm{n}_{2}=62\right)\end{array}$ & 95 percent CI & p-value & \\
\hline Below normal & 115 & 92 & 23 & 4.22 & $2.22-8.01$ & $<0.01^{\mathrm{s}^{*}}$ \\
$(<9 \mathrm{mg} / \mathrm{d})$ & $(60.2 \%)$ & $(48.2 \%)$ & $(12.0 \%)$ & & & \\
Normal & 62 & 26 & 36 & 0.18 & $0.09-0.35$ & $1.60^{\text {ns * }}$ \\
$(9-11 \mathrm{mg} / \mathrm{dl})$ & $(32.5 \%)$ & $(13.6 \%)$ & $(18.8 \%)$ & & & \\
Above normal & 14 & 11 & 3 & 1.83 & $0.49-6.82$ & $0.36^{\mathrm{ns}^{* *}}$ \\
$(>11 \mathrm{mg} / \mathrm{dl})$ & $(7.3 \%)$ & $(5.8 \%)$ & $(1.6 \%)$ & & & \\
\hline
\end{tabular}

${ }^{*}$ Chi-square test. ${ }^{* *}$ Fisher's exact test. ${ }^{\text {s_Significant. }}{ }^{\text {ns }}$-Not significant

Table-IIshows the association of serum calcium and pruritus in the study subjects. Statistically significant association was found between hypocalcaemia and pruritus (Odds ratio 4.22, $\mathrm{p}<0.01$ ).

No such association was found between normocalcaemia or hypercalcaemia and pruritus.
Table-3 shows the serum phosphate level of the study subjects in three categories. Eighty six (45 percent) subjects had normal serum phosphate $(3-4.5 \mathrm{mg} / \mathrm{dL})$. Sixty four (34 percent) were hypophosphataemic (Serum phosphate $<3 \mathrm{mg} / \mathrm{dL}$ ). Forty one (21 percent) subjects were hyperphosphataemic (> $4.5 \mathrm{mg} /$ $\mathrm{dL}$ ).No significant association was found between serum phosphate level and pruritus.

Table-III

Association of serum phosphate level with pruritus.

\begin{tabular}{lcccccc}
\hline Serum phosphate & Total & \multicolumn{2}{c}{ Pruritus } & Odds & 95 percent & p- \\
& & $\begin{array}{c}\text { Present } \\
\left(\mathrm{n}_{1}=129\right)\end{array}$ & $\begin{array}{c}\text { Absent } \\
\left(\mathrm{n}_{2}=62\right)\end{array}$ & $\begin{array}{c}\text { ratio } \\
\text { value }\end{array}$ & & \\
\hline Below normal & 64 & 40 & 24 & 0.71 & $0.38-1.34$ & $0.29^{\text {ns }}$ \\
$(<3.0 \mathrm{mg} / \mathrm{dl})$ & $(33.5 \%)$ & $(20.9 \%)$ & $(12.6 \%)$ & & & \\
Normal & 86 & 63 & 23 & 1.62 & $0.87-3.01$ & $1.88^{\text {ns }^{*}}$ \\
$(3.0-4.5 \mathrm{mg} / \mathrm{dl})$ & $(45.0 \%)$ & $(33.0 \%)$ & $(12.0 \%)$ & & & \\
Above normal & 41 & 26 & 15 & 0.79 & $0.38-1.63$ & $0.53^{\text {ns * }}$ \\
$(>4.5 \mathrm{mg} / \mathrm{dl})$ & $(21.5 \%)$ & $(13.6 \%)$ & $(7.9 \%)$ & & & \\
\hline
\end{tabular}

${ }^{*}$ Chi-square test. ${ }^{\text {ns }}$-Not significant.

Table-IV

Association of serum Calcium-Phosphate product with pruritus.

\begin{tabular}{|c|c|c|c|c|c|}
\hline & & $\begin{array}{c}\text { Pruritus } \\
\text { No }(\%)\end{array}$ & $\begin{array}{c}\text { Total (\%) } \\
\text { Yes (\%) }\end{array}$ & P value* & \\
\hline S. Calcium & $\leq 55$ & $57(29.8 \%)$ & $118(61.8 \%)$ & 175(91.6\%) & $0.914^{\mathrm{ns}}$ \\
\hline $\begin{array}{l}\text { Phosphate } \\
\text { product } \\
\text { Total }\end{array}$ & $>55$ & $\begin{array}{c}05(2.6 \%) \\
62(32.5 \%)\end{array}$ & $\begin{array}{c}11(5.8 \%) \\
129(67.5 \%)\end{array}$ & $\begin{array}{c}16(8.4 \%) \\
191(100.0 \%)\end{array}$ & \\
\hline
\end{tabular}

${ }^{*}$ Chi-square test. ${ }^{\text {ns }}$ - Not significant. 
Table- 4 shows the serum calcium-phosphate product of the study subjects in two categories. One hundred and seventy five (91.6 percent) subjects had serum calcium phosphate product d" $55 \mathrm{mg}^{2} / \mathrm{dL}^{2}$. It was $>55 \mathrm{mg}^{2} / \mathrm{dL}^{2}$ in $16(8.4$ percent) subjects. No significant association was found between serum calcium-phosphate product and pruritus.

\section{Discussion}

One hundred and ninety one patients of chronic kidney disease (CKD) Stage 5 on maintenance haemodialysis (HD) were included in this study. Majority of cases aged between 35 and 55 years (45\%). No significant association was found between different age group and pruritus.(Table 1) The age distribution was similar to that of the previous study conducted in Bangladesh. ${ }^{21}$ That was a descriptive, cross sectional study done regarding the prevalence of Chronic Kidney Disease. One hundred and thirteen $(59.2 \%)$ were males and seventy eight $(40.8 \%)$ were females. (Table 2) Similar sex distribution was found in the study on CKD patients in Bangladesh. ${ }^{21}$

One hundred and fifteen (60.2\%) were urban and 76 (39.8\%) were rural. (Table 1) Similar distribution of residence was found on patients on maintenance haemodialysis, in urban and rural areas of Bangladesh. ${ }^{22,} 23$

Glomerular disease $(77,40 \%)$ was the most prevalent cause of chronic kidney disease (CKD), followed by diabetes mellitus $(61,32 \%)$ and hypertension $(21,11 \%)$. No cause could be identified in 20 patients (10\%). (Fig 1) Similar etiological distribution was found in a study on patients on maintenance haemodialysis, in urban and rural areas of Bangladesh. ${ }^{22,} 23$ In their study, obstructive nephropathy and adult polycystic kidney disease were found in 5\% and $2 \%$ cases respectively, and no cause could be identified in 16 patients (8\%).In this study, obstructive nephropathy and adult polycystic kidney disease were found in $6 \%$ and $1 \%$ cases respectively. (Fig 1)

Generalized weakness was the most common clinical feature found in 187 (98\%) patients. Other common features were gastrointestinal symptoms (anorexia, nausea and vomiting), oliguria, hypertension, anaemia, oedema and hyperpigmentation found in 178 (93\%), 171 (90\%), 162 (85\%), $156(82 \%), 148(78 \%)$ and $141(74 \%)$ patients respectively. Pruritus was found in 129 patients (68\%). (Fig 2) Similar clinical features were observed on CKD (stage 5) patients on maintenance haemodialysis in Iran, ${ }^{24}$ which found pruritus in $60 \%$ of study population. same distribution of clinical features was found in Bangladesh among nondialytic patients with Chronic Kidney Disease. ${ }^{25}$

In previous studies, the reported prevalence of pruritus has been higher $(84 \%),{ }^{26}$ while in some other studies, it has been lower than that in our study. On CKD patients in Bangladesh it is $(53 \%){ }^{4}$ Inclusions of only stage-5 patients in this study may explain this discrepancy. Pruritus was observed in $58.8 \%{ }^{27}, 41.9 \%{ }^{28}$ and $70 \%{ }^{29}$ of the patients in different studies from Japan. These differences may be due to the prevailing climatic conditions. Comparison of these results shows that, generally, more than half of the patients complained of pruritus in most studies.

In our study, one hundred and fifteen $(60.2$ percent) subjects were hypocalcaemic (serum calcium $<9 \mathrm{mg} / \mathrm{dl}$ ), sixty two (32.5 percent) subjects had normal serum calcium $(9-11 \mathrm{mg} /$ dl) and fourteen (7.3 percent) subjects were hypercalcaemic (> $11 \mathrm{mg} / \mathrm{dl}$ ). Significant association was found between hypocalcaemia and pruritus $(\mathrm{P}=<0.01)$ (Table 2$)$. Some studies found significant association between hypocalcaemia with pruritus ${ }^{30}$. In this study serum calcium was below normal in $54.2 \%$ of the patients with pruritus and $44.7 \%$ of patients without pruritus. Some other studies showed that the serum calcium concentration was significantly higher in patients with pruritus when compared with those without pruritus. ${ }^{31,32}$.In the present study, majority of the cases with pruritus had decreased levels of serum calcium. However, some other investigators, found no significant association between serum calcium and pruritus. ${ }^{28,33}$

Eighty six (45 percent) subjects had normal serum phosphate $(3-4.5 \mathrm{mg} / \mathrm{dl})$ level. Sixty four (33.5 percent) were hypophosphataemic 
(Serum phosphate $<3 \mathrm{mg} / \mathrm{dl}$ ). Forty one $(21.5$ percent) subjects were hyperphosphataemic (> $4.5 \mathrm{mg} / \mathrm{dl}$ ) (Table 3). One hundred and seventy five (91.6 percent) subjects had serum calcium phosphate product d" $55 \mathrm{mg}^{2} / \mathrm{dl}^{2}$. It was $>55$ $\mathrm{mg}^{2} / \mathrm{dl}^{2}$ in 16 (8.4 percent) subjects (Table 4). similar metabolic profile is found in nondialytic CKD patients in Bangladesh. ${ }^{25}$

Regarding the association of metabolic variables and pruritus, statistically significant association was found between hypocalcaemia and pruritus. Neither did abnormal serum phosphate level $(\mathrm{P}=0.310)$ nor high serum calcium-phosphate product $\left(>55 \mathrm{mg}^{2} / \mathrm{dl}^{2}\right)$ level showed any significant association with pruritus (Table 2, 3, 4). Similar association was found in a study in CKD patients on maintenance haemodialysis in Iran, ${ }^{24}$ in which no significant association was found between pruritus and age, gender, serum phosphate levels and the Ca-P product in hemodialysis patients. Another study in Iran observed higher incidence of pruritus in CKD patients with hyperphosphataemia. ${ }^{34}$ some studies found no association between serum phosphate levels and pruritus. ${ }^{28,29}$ These findings were similar to our study.

Some previous studies observed that there was a significant association between the $\mathrm{Ca}-\mathrm{PO}_{4}$ product and pruritus, ${ }^{35,}{ }^{36}$ some other found no association between the $\mathrm{Ca}-\mathrm{PO}_{4}$ product and pruritus $^{30}$ which is similar to our result $(\mathrm{P}=0.914)$. A small sample size and low prevalence of hyperphosphataemia among the study subjects might be the reason behind the failure to find such associations in this study.

\section{Conclusion}

CKD has a progressive course in most cases, and final results may be End Stage Renal Disease (ESRD).Hemodialysis is one of the mainstays in the treatment of these patients. Disturbance in calcium (Ca) and phosphate (PO4) metabolism are observed in these patients. One of the most common cutaneous manifestations in patients on hemodialysis is pruritus. The aim of this study is to evaluate the association between pruritus and serum calcium, phosphate and serum calcium phosphate product in patients on maintenance haemodialysis.
Our study showed that most patients with pruritus had serum calcium levels in the below normal range. Thus, good control of serum calcium levels may have a role in reducing uraemic pruritus in these patients.

\section{References:}

1. Arend, Armitage, Clemmons, Cecil Medicin, (2008), $23^{\text {rd }}$ ed, Vol. 1, Chapter 131, Chronic Kidney Disease.

2. Rashid HU. (2002), Bangladesh Renal Registry Report (1986-1996). Bangladesh renal J; 21(1): 25-28.

3. Rennke HG, Denker BM. (2010), Renal pathophysiology: the essentials. 3rd ed. Philadelphia: Lippincott Williams \& Wilkins. p. 18.

4. JA Leena, MU Noman, MMSU Islam, AS Ahmed, DS Ahmed, MM Rahman. (2012), Cutaneous Manifestations of Chronic Kidney Disease-An Observational Study in 100 Cases. Faridpur Med. Coll. J;7(1): 33-36.

5. Banerjee S. (2007), Cutaneous manifestations in renal failure patients: Acase series. Indian J Dermatol Venereol Leprol; 73:106-8.

6. Ghaderi R, Mohamadi-Fard M. (2006), Comparison of effectiveness of emollients and heliotherapy for pruritus relief in hemodialysis patients. Horizon of Medical Sciences;12(1):42-7.

7. Massry SG, Popovtzer MM, Coburn JW et al. (1968), Intractable pruritus as a manifestation of secondary hyperparathyroidism in uremia. Disappearance of itching after subtotal parathyroidectomy. N Engl J Med; 279: 697-700.

8. Bencini PL, Montagnino G, Citterio A, Graziani G, Crosti C,Ponticelli C. (1985), Cutaneous abnormalities in uremic patients.Nephron.40:31621.15 .

9. Etter L, Myers SA. (2002), Pruritus in systemic disease: Mechanisms and management. Dermatol Clin.;20:459-72.16.

10. Garssen J et al. (1999) UVB exposure-induced systemic modulation of TH1- and TH2-mediated immune responses. Immunology 97: 506-514.

11. Kimmel M et al. (2006) The role of micro-inflammation in the pathogenesis of uremic pruritus in haemodialysis patients. Nephrol Dial Transplant 21: 749-755.

12. Qureshi AR et al. (2002) Inflammation, malnutrition, and cardiac disease as predictors of mortality in hemodialysis patients. J Am Soc Nephrol 13 (Suppl): S28.S36.

13. Umueuchi $\mathrm{H}$ et al. (2003) Involvement of central $\mu-$ opioid system in the scratching behavior in mice, and the suppression of itch by the activation of $\mu$-opioid system. Eur J Pharmacol 477: 29-35. 
14. Kumagai $\mathrm{H}$ et al. (2004) Prospects for a novel kappaopioid receptor agonist, TRK-820, in uremic pruritus. In Itch, Basic Mechanisms and Therapy, 279-286 (Eds Yosipovitch G et al.) New York, NY: Dekker.

15. Menon GK, Elias PM. (1991), Ultrastructural localization of calcium in psoriatic and normal human epidermis. Arch Dermatol ; 127: 57-63.

16. Elias PM, Nau P, Hanley K et al. (1998), Formation of the epidermal calcium gradient coincides with key milestones of barrier ontogenesis in the rodent. J Invest Dermatol; 110: 399-404.

17. Kimmel M et al. (2006) The role of micro-inflammation in the pathogenesis of uremic pruritus in haemodialysis patients. Nephrol Dial Transplant 21: 749-755.

18. Hasan MJ, kashem MA, Rahman MH, QuddhuhR, Rahman M, sharmeen A, Islam N. (2012), Prevalence of Chronic Kidney Disease (CKD) and identification of associated risk factors among rural population by mass screening. CBMJ, Vol 01 : P. 20-26.

19. Ahmed, MA Rahim, Ali M Z, MM Iqbal. (2012), Prevalence of primary renal diseases among patients on maintenance haemodialysis: A hospital based study.KYAMC Journal, Vol. 2, No.-2.

20. Ahmed SS, Ali MZ, Laila TR, Moniruzzaman. (2013), Outcome of Urgent Hemodialysis in Chronic Kidney Disease in a Rural Tertiary Care Hospital.KYAMC Journal. Vol. 3, No.-2.

21. Ramin Tajbakhsh, Hamid Reza Joshaghani, Faranak Bayzayi, Mahboobeh Haddad, Mostafa Qorbani (2013),Association between pruritus and serum concentrations of parathormone, calcium and phosphorus in hemodialysis patients Saudi J Kidney Dis Transpl.24(4):702-6.

22. Saha M, Faroque MO, Alam KS, Alam MM, Ahmed S.(2012), Chronic Kidney Disease specific cardiovascular risk factors among nondialytic patients with Chronic Kidney Disease stage-V-An experience of a specialized hospital. Bangladesh Med Res Counc Bull; 38: 18-22.
23. Mathur VS et al.(2010), A longitudinal study of uremic pruritus in hemodialysis patients.Clin J Am Soc Nephrol. 2010 Aug; 5(8):1410-9.

24. Szepietowski JC, Sikora M, Kusztal M, Salomon J, Magott M, Szepitowski T. (2000), Uremic pruritus: a clinical study of maintenance hemodialysis patients. J Dermatol.29:621-6.

25. Akhyani M, Ganji MR, Samadi N, Khamesan B, Daneshpazhooh M. (2005), Pruritus in hemodialysis patients. BMC Dermatol; 24: 70-80.

26. Yazdanpanah M, Mojahedi M, Ebrahimi Rad M, Birjandi M. (2006), Cutaneous manifestations in hemodialysis patients with chronic renal failure. Mashhad Univ Med Sci J; 25:92, 509.

27. Ramin Tajbakhsh, Hamid Reza Joshaghani, Faranak Bayzayi, Mahboobeh Haddad, Mostafa Qorbani (2013),Association between pruritus and serum concentrations of parathormone, calcium and phosphorus in hemodialysis patients Saudi J Kidney Dis Transpl.24(4):702-6.

28. Narita I et al. (2006) Aetiology and prognostic significance of severe uremic pruritus in chronic hemodialysis patients. Kidney Int 69: 1626-1632.

29. Szepietowski J. (1996), Selected elements of the pathogenesis of pruritus in hemodialysis patients: My own study. Med Sci Monit; 343-7.

30. Kuypers D, Claes K, Evenepoel P, Maes B, Vanrenterghem Y. (2004), A prospective proof of concept study of the efficacy of tacrolimus ointment on uremic pruritus (UP) in patients on chronic dialysis therapy. Nephrol Dial Transplant; 19, 1895-901.

31. Gatmiri SM, Mahdavi-MM, Pezeshki LM, , Abbasi M (2013). Uremic Pruritus and Serum Phosphorus Level. Acta Medica Iranica; 51 (7):477-481.

32. Kentaro O, Ikuo I, Haruki A, et al. (2001), Risk factors for uremic pruritus in long-term hemodialysis patients. J Jpn Soc Dial Ther;12;1469-77.

33. Chou FF et al. (2000) A study on pruritus after parathyroidectomy for secondary hyperparathyroidism. J Am Coll Surg 190: 65-70. 